\title{
Soil Carbon Stock and soil physico-chemical properties under A.saligna plantation in Northern Ethiopia
}

\author{
Mulat Assefa ${ }^{1}$, Emiru Birhane ${ }^{1}$, Fisseha Birhanu ${ }^{2}$, Girmay Abraha ${ }^{3}$, and Niguse \\ Gebremedhin ${ }^{4}$ \\ ${ }^{1}$ Affiliation not available \\ ${ }^{2}$ Tigray Agricultural Research Institute \\ ${ }^{3}$ Mekelle University College of Dryland Agriculture and Natural Resources \\ ${ }^{4}$ World Agroforestry Center
}

June 9, 2020

\begin{abstract}
Afforestation of degraded lands using both exotic and indigenous species is used to reduce land degradation and to reforest degraded areas. Acacia saligna is one of the common exotic plantation species planted in Ethiopia. This study analyzed the existing carbon stock and some soil physico-chemical properties of A. saligna plantation at two districts in Tigray, northern Ethiopia. Soil samples were collected from 204 samples at three soil depths from plantation site and adjacent grazing lands. Paired t-test was used to analyze data. Soil organic carbon (SOC) stock was higher at lower depth (40-60cm) than middle and upper depths at plantation sites while the second depth $(20-40 \mathrm{~cm})$ was found higher SOC at grazing lands. Furthermore, in Mai-Brazio, soil properties except Total nitrogen(TN) and Available Phosphorus (Av,P), Cation Exchange Capacity (CEC), Available Potassium $(\mathrm{Av}, \mathrm{K})$ and soil $\mathrm{pH}$ were significantly $(\mathrm{P}<0.05)$ higher than adjacent grazing lands While CEC and Av.K were non-significant in Barka-Adisbha site $(\mathrm{p}>0.05)$. Area converted to plantation site showed lower soil bulk density than the open grazing land. Further, CEC is negatively correlated $(\mathrm{P}<0.001)$ with soil $\mathrm{pH}$, this may shows that CEC is affected by the variation of soil $\mathrm{pH}$.
\end{abstract}

\section{Hosted file}

Mulat A. SOC under A.saligna plantation.pdf available at https://authorea.com/users/331368/ articles/458051-soil-carbon-stock-and-soil-physico-chemical-properties-under-a-salignaplantation-in-northern-ethiopia 